\title{
CORRECTION
}

\author{
(A) Check for updates \\ Cite this: Green Chem., 2020, 22 \\ 5504 \\ DOI: $10.1039 /$ d0gc90081h \\ rsc.li/greenchem
}

\section{Correction: An efficient metal-free pathway to vinyl thioesters with calcium carbide as the acetylene source}

\author{
Konstantin S. Rodygin ${ }^{a}$ and Valentine P. Ananikov $\star^{a, b}$ \\ Correction for 'An efficient metal-free pathway to vinyl thioesters with calcium carbide as the acetylene \\ source' by Konstantin S. Rodygin et al., Green Chem., 2016, 18, 482-486. DOI: 10.1039/C5GC01552A.
}

Following reader correspondence, the authors note that misprints appear in Table 2, footnote c. The correct text for Table 2, footnote c should be: "Experimental conditions for a larger scale: powdered $\mathrm{CaC}_{2}(0.08 \mathrm{~mol})$; thiophenol $(0.04 \mathrm{~mol})$; $\mathrm{H}_{2} \mathrm{O}$ (0.12 mol), dried DMF."

The above values are in-line with those presented in the manuscript text and the ESI.

The Royal Society of Chemistry apologises for these errors and any consequent inconvenience to authors and readers.

\footnotetext{
${ }^{a}$ Saint Petersburg State University, Universitetsky pr. 26, Stary Petergof 198504, Russia

${ }^{b}$ Zelinsky Institute of Organic Chemistry, Russian Academy of Sciences, Leninsky pr. 47, Moscow 119991, Russia. E-mail: val@ioc.ac.ru
} 